\title{
An Analysis of the Supplier Selection Process
}

\author{
Rohit Verma \\ DePaul University, Chicago, IL, U.S.A. \\ Madeline E. Pullman \\ Southern Methodist University, Dallas, TX, U.S.A.
}

\begin{abstract}
Customers select suppliers based on the relative importance of different attributes such as quality, price, flexibility, and delivery performance. This study examines the difference between managers' rating of the perceived importance of different supplier attributes and their actual choice of suppliers in an experimental setting. We use two methods: a Likert scale set of questions, to determine the importance of supplier attributes; and a discrete choice analysis (DCA) experiment, to examine the choice of suppliers. The results indicate that although managers say that quality is the most important attribute for a supplier, they actually choose suppliers based largely on cost and delivery performance.
\end{abstract}

\section{Introduction}

During recent years supply chain management and the supplier (vendor) selection process has received considerable attention in the business management literature. In one of the widely cited articles on operations strategy, Miller et al. [35] classify supply strategies as one of the strategic operating choices. Additionally, with the increase in use of total quality management (TQM) and just-in-time (JIT) concepts by a wide range of firms, the supplier selection question has become extremely important. In a recent study, Flynn et al.[18] found supplier involvement to be an important dimension of quality management. Bankar and Khoska [4] classify the supplier selection process as an important operations management (OM) decision area. They suggest that OM research should attempt to identify the supply chain management practices that provide competitive advantage. Karmarkar [29] also identifies supply chains as multi-disciplinary in nature and recommends an integrated $\mathrm{OM} / \mathrm{marketing}$ approach.

Dickson [15], in one of the early works on supplier selection, identified over twenty supplier attributes which managers tradeoff when choosing a supplier. Since then, a number of conceptual and empirical articles on supplier selection have appeared [43]. The conceptual articles by Ansari and Modarress [2, 3], Benton and Krajewski [6], Bernard [7], Browning et al. [9], Burton [10], Hahn et al. [24], Jackson [28], Kraljic [30], Sheth [38], and Treleven [39] are 
examples of publications emphasizing the strategic importance of the supplier selection process. The above articles (and several others) highlight the tradeoff among quality, cost and delivery performance measures in the supplier selection process.

Weber and Current [42] proposed a multi-objective approach to vendor selection. Their methodology provides a useful decision support system for a purchasing manager faced with multiple vendors and tradeffs such as price, delivery reliability, and product quality. In Weber and Current's [42] approach, the goal is to determine an acceptable set of solutions (number of vendors and order size from each vendor).

A number of empirical articles on supplier selection have also appeared. Based on empirical data collected from 170 purchasing managers, members of the National Association of Purchasing Managers, Dickson [15] identified quality, cost, and delivery performance history as the three most important criteria in vendor selection. Cardozo and Cagley [11], Chapman [12], Chapman and Carter [13], Dempsey [14], Hakansson and Wootz [26], Monczka et al. [36], Wagner et al. [41] and several other authors have evaluated the relative importance of quality, cost, delivery performance, and other supplier attributes. According to a review of 74 articles discussing supplier selection criteria, quality was perceived to be most important followed by delivery performance and cost [43]. In summary, most of the articles referenced above suggest that managers perceive quality to be the most important supplier attribute. The conceptual articles emphasize that managers should not select suppliers based on low cost only but should consider quality, delivery performance and other attributes.

While the supplier selection literature is rich in terms of: (a) conceptual and empirical work and (b) decision support methods for purchasing managers, none of the articles cited above has studied how managers actually choose suppliers. The past empirical articles are based on the managers' rating of the perceived importance of different supplier attributes. An actual choice of supplier involves evaluating the characteristics of the suppliers based on their attributes and selecting one or more supplier(s) that best suit the needs of the firm.

It can be argued that it is extremely difficult for any one supplier to excel in all dimensions of performance. For example, a high quality supplier might not be the one with lowest cost components. It is also possible that the components delivered by a particular supplier excel in a few quality dimensions (reliability, features) while some other supplier might be superior in other quality dimensions (for example, durability or aesthetics). Therefore an actual choice generally involves tradeoff among the attribute levels of different suppliers [5, 32].

The objective of this study was to test how managers actually choose suppliers. The empirical results presented later in this article show that the relative importance of different supplier attributes in actual choice of suppliers are not the same as the perceived importance of the attributes. For example, it appears that managers perceive quality to be the most important attribute but they assign more weight to delivery performance and/or cost when actually 
choosing a supplier. These results imply that even though the managers believe that several attributes (for example, quality) are important for supplier selection, in actual practice the low cost supplier is selected. We believe that these results have important implications for operations strategy implementation and supply chain management. To our knowledge, none of the published studies has presented such analyses of the supplier selection process.

Specifically, we examine the perceived importance of supplier selection criteria (quality, cost, delivery performance) and identify the relative weights of the attributes in actual selection of suppliers. In addition to quality, cost, and delivery we also identify the relative importance of -flexibility, the fourth operations objective identified by Hayes and Wheelwright [27] and other operations strategy researchers $[1,16]$. The following two research questions explore the above ideas:

Research Question I: What are the perceived importance of quality, cost, delivery, and flexibility attributes in the supplier selection process?

Research Question II: How do managers tradeoff among quality, cost, delivery and flexibility attributes when actually choosing a supplier?

We used two different data collection and analyses procedures to explore the above research questions. A survey instrument containing Likert-type scale questions was used to explore Research Question I. We used an econometric procedure known as discrete choice analysis (DCA) for quantifying the relative weights of attributes when actual supplier choice is made (Research Question II). The following sections describe the research design, data collection and analyses procedures, and discuss the empirical results.

\section{Research Method}

An empirical study was designed to evaluate the supplier selection process. The sample group consisted of manufacturing companies, specifically metal processing and producers of small machine tools and tooling in the western United States. The population included 323 companies with SIC codes of 33, 34, and 35 registered with two western states (Utah and Arizona) in 1994. The actual data from the managers were collected during the first half of 1995.

Operations managers or the managers with purchasing/supplier selecting responsibility were contacted by phone and were requested to participate in the survey. It was also ensured that the company manufactured appropriate product(s) (with SIC code 33, 34 or 35), and confirmed that the company employed at least 15 people. From the original population, 139 managers agreed to participate in the study. Survey instruments along with the cover letter, a postage-paid business reply envelope, and a forwarding letter from the management department of a large state university in the western United States were mailed to the managers. 
As mentioned earlier, a Likert-type scale was used to explore the perceived importance of various supplier attributes. The respondents were asked to evaluate the relative importance of five broad supplier attributes from 1 (least important) to 5 (most important). Past research in supplier selection has identified quality, cost and delivery performance as important attributes. For this study, delivery performance is measured with two separate attributes, delivery leadtime and on time delivery performance. Both of these criteria are important for the customer's production planning and scheduling, particularly for JIT manufacturers [3]. Flexibility has been identified as another operations objective (or competitive priority) and therefore was included as one of the attribute [27]. Table 1 lists the five items used to explore Research Question I.

Next, we used discrete choice analysis (DCA - also known as choice-based conjoint analysis) to identify the actual supplier choice process. Past research in econometrics, marketing, and other social sciences has shown that DCA is an effective methodology for analyzing choices in complex decision making situations (such as supplier selection) [5, 33]. Discrete choice analysis is a systematic approach for identifying the relative weights of attributes among which the decision maker tradeoffs when choosing an alternative from a possible set of alternatives. This approach is based on an econometric model called multinomial logit ( $\mathrm{MNL}$ ), which uses a maximum likelihood estimation scheme to maximize the probability of choosing an alternative with given attribute levels. This approach has been successfully used for a variety of choice or tradeoff-type applications in marketing, consumer research, transportation, recreation and leisure research, hospitality, sociology and other social sciences (for example Refs. [19, 31, 40]). Later in this article we will present a brief overview of DCA for the purpose of explaining the research approach and the data analysis.

On a scale 1 to 5 , rate the relative importance of the following supplier attributes. Assume that you are evaluating the attributes for suppliers of key components/raw materials:

\begin{tabular}{|c|c|c|c|c|c|}
\hline & Least important & & & & Most important \\
\hline $\begin{array}{l}\text { Unit cost of components/raw } \\
\text { materials }\end{array}$ & 1 & 2 & 3 & 4 & 5 \\
\hline $\begin{array}{l}\text { Quality of components/raw } \\
\text { materials }\end{array}$ & 1 & 2 & 3 & 4 & 5 \\
\hline Delivery lead-time & 1 & 2 & 3 & 4 & 5 \\
\hline On-time delivery performance & 1 & 2 & 3 & 4 & 5 \\
\hline Flexibility in changing the order & 1 & 2 & 3 & 4 & 5 \\
\hline
\end{tabular}

Table 1. Perceived importance of supplier attributes

Discrete choice analysis involves designing several experimental profiles (alternatives) of the decision situations (for example - profiles of suppliers with different quality, cost, delivery and flexibility attribute levels) and asks the decision maker(s) to choose an alternative from a set of possible choices. Therefore the choice (or tradeoff) pattern can be hypothesized to be dependent on the attribute levels used to design the experimental profiles (the alternatives are designed according to pre-determined experimental design procedures and hence the researcher controls the levels of independent variables). The distribution of dependent variable (choice) is determined by the decision-maker (for example, managers). 
Experimental design for a discrete-choice analysis starts with the identification of determinant attributes used by the decision-maker in the evaluation process. Market surveys, interviews, case studies, and/or focus groups can be conducted to identify a set of relevant attributes. In the case of supplier selection process however, the past research has identified quality, cost, delivery lead time, on time delivery, and flexibility as important attributes. Therefore, in this study, the five attributes listed in Table 1 were used as supplier attributes.

After the identification of the relevant attributes and their possible numerical/categorical values, experimental design procedures are utilized to generate a set of alternatives. According to Louviere [32], most practical conjoint studies involving four or more attributes at two or more levels rely on fractional factorial designs to limit the number of experimental profiles. Green and Srinivasan [20] and Greenberg [22] suggest that respondents evaluate no more than 30 profiles. Most researchers attempt to limit the number of profiles to 16 or less to prevent degradation of response quality. To reduce the number of profiles, researchers can do both of the following: (a) limit the number of attributes and attribute levels and (b) use fractional factorial designs capable of estimating all main-effects and a limited number of interactions. Over the last several years, a number of fractional factorial design procedures have been developed by applied statisticians which can be used to design discrete choice experiments. See Refs. [8, 21, 25, 32, 34] for detailed discussions on fractional factorial design of experiments.

In order to limit the complexity of the experimental design, we chose to consider only two levels of each of the five attributes. A full profile design would require 25 (32) experimental profiles to estimate the main effects and all possible interactions among these independent variables. While a small number of profiles are required for main effects only, Hagerty [23] recommends that whenever possible, two-way interactions among the attributes should be estimated also. Thus to get main and two-way effects, we used a standard one-half fraction of the 25 factorial design [25]. This design makes it possible to estimate all the main effects and two-way interaction terms with only 16 profiles.

Table 2 lists the five attributes and their two levels and experimental design codes. The design codes -1 and +1 represent the two levels of the attributes. The design procedure was "balanced" therefore -1 and +1 levels appear an equal number of times for all the attributes in the experimental profiles. This procedure assures no bias towards +1 levels or -1 levels in the experimental design. The fractional factorial design matrix used to generate the supplier profiles is presented in Table 3.

\begin{tabular}{lcc}
\hline Attributes & Design code: -1 & Design code: +1 \\
\hline Unit cost of components/raw materials & lower than competitors & higher than competitors \\
Quality of components/raw materials & meets minimum quality standards & far exceeds minimum quality standards \\
Delivery lead-time & shorter than competitors & longer than competitors \\
On-time delivery & sometimes late & alway time \\
Flexibility in changing the order & lower than competitors & higher than competitors
\end{tabular}

Table 2. Supplier attributes 
A typical discrete-choice experiment shows two or more alternatives to the decisionmaker at the same time and asks him/her to choose the preferred alternative. This choice task is repeated several times (equal to number of product profiles generated by the fractional factorial design). Since the researcher manipulates the attributes (independent variables), the decision-maker's choice (dependent variable) can be hypothesized to be affected by the determinant attributes.

\begin{tabular}{lccccc}
\hline Profile \# & Cost & Quality & Lead-time & On-time delivery & Flexibility \\
\hline 1 & -1 & -1 & -1 & -1 & -1 \\
2 & -1 & -1 & -1 & +1 & +1 \\
3 & -1 & -1 & +1 & -1 & +1 \\
4 & -1 & -1 & +1 & +1 & +1 \\
5 & -1 & +1 & -1 & -1 & -1 \\
6 & -1 & +1 & -1 & +1 & -1 \\
7 & -1 & +1 & +1 & -1 & +1 \\
8 & -1 & +1 & -1 & +1 & +1 \\
9 & +1 & -1 & -1 & -1 & -1 \\
10 & +1 & -1 & +1 & +1 & +1 \\
11 & +1 & -1 & +1 & -1 & -1 \\
13 & +1 & +1 & -1 & -1 & +1 \\
14 & +1 & +1 & +1 & +1 & +1 \\
15 & +1 & +1 & +1 & -1 & -1 \\
\hline 6 & +1 & +1 & & +1 & \\
\hline
\end{tabular}

Table 3. Fractional factorial design matrix

The experimental design matrix presented in Table 3 was used to generate discrete choice experiments for the managers. The 16 profiles presented in Table 3 were paired with their respective "foldover" design. The attribute levels in a foldover design are the opposite of the original design. For example, the design code for all variables in the first profile is -1 , therefore the foldover design code for all variables will be +1 . The discrete choice experiment asked the managers to choose between a supplier with attributes presented in Table 3 , its foldover design supplier, or neither. The managers made 16 separate choices. A sample discrete choice set is represented in Table 4.

\section{Data Analysis Procedure}

The data collected from the Likert type scale questions can be assumed to be on an interval scale and hence means can be compared as a measure of relative perceived importance of the supplier attributes [17]. Past empirical studies have used this analysis procedure. (Alternatively, medians can be compared if the data cannot be assumed to be interval scaled).

The data collected by the discrete choice analysis are categorical in nature. The multinomial logit ( $\mathrm{MNL}$ ) regression is the appropriate statistical procedure for analyzing such choice data [5]. A MNL regression model represents the probability of selecting an alternative from a possible set of alternatives. The multinomial logit model is expressed as 


$$
P_{i j}=\frac{e^{\mu V_{i j}}}{\sum_{k=1, K} e^{\mu \mu V_{k j}}}
$$

where $P_{i j}$ represents the probability of selecting alternative $i$ from the $j$ th choice set containing $\mathrm{K}$ possible choices. $V_{i j}$ in Equation (1) represents the systematic utility of alternative I in choice set $\mathrm{j}$. The multinomial logit model assumes that the errors are independent and identically distributed according to a Gumbel distribution with a scale parameter $m$. Representing a choice alternative as a bundle of its attributes, and by assuming an additive utility function, $V_{i j}$ can be calculated in the following manner

$$
V_{i j}=\sum_{l=1, L} \beta_{l} x_{i j l}
$$

where $x_{i j l}$ is the level of attribute $l$ of alternative $i$ in choice set $j$ and $\beta_{l}$ is the relative utility weight (part-worth utility) associated with attribute $l$ [5]. The total number of attributes is $L$. There are a number of general approaches to finding $\beta$ parameters, however, in practice the maximum likelihood estimation procedure is used. A maximum likelihood estimator is the value of the $\beta$ parameters for which the observed sample is most likely to have occurred [5]. Therefore the likelihood function for $M$ subjects can be represented as

$$
L=\prod_{m=1, M} \prod_{l=1, L} \prod_{j=1, J} P_{i j}^{Y_{i j m}}
$$

$Y_{i j m}=1$ if subject $\mathrm{m}$ chooses alternative $i$ in choice set $\mathrm{j}, Y_{i j m}=0$ otherwise.

We used the NTELOGIT program to estimate $\beta$ parameters for the supplier selection process [37]. NTELOGIT calculates the $\beta$ parameters for an aggregate sample data using the maximum likelihood estimation procedure. The "goodness-of-fit" statistics were also calculated. Please refer to Appendix A for details on these statistics.

\section{Results}

The survey was mailed to 139 managers and 58 completed useable surveys were received for a response rate of $41.7 \%$. Table 5 presents the descriptive statistics of data collected by the Likert-Type Scale questions. The results show that managers perceive "Quality" to be most important supplier attribute, followed by "On Time Delivery" and "Unit Cost of Parts". This result is consistent with the past studies, which have shown that managers perceive quality to be the most important supplier attribute [43]. It is interesting to note that the first delivery performance measure "On Time Delivery" is rated to be more important than "Unit Cost" but the second measure of delivery performance "Delivery Lead Time" is rated to be less important than "Unit Cost." Flexibility in changing the order was perceived to be the least important among the five attributes. 
Table 5 also lists the standard deviations for the five variables. Since the standard deviation values are relatively large (between 0.69 to 1.08 ), statistical tests are not likely to show differences between the mean perceived importance of the variables. All possible multiple pairwise comparisons were conducted and only the mean of "Quality" was statistically different from all the other variables. The median perceived importances for the five variables are also shown in Table 5. This shows that quality is perceived to be the most important, followed by equal weight for unit cost and delivery performance measures.

Table 6 presents the MNL regression model for the supplier choice process. NTELOGIT was used to estimate MNL regression model from data collected by the discrete choice

\begin{tabular}{lcccc}
\hline Variables & Rank & Mean & Median & Std. deviation \\
\hline Cost & III & 3.96 & 4 & 0.922 \\
Quality* & I & 4.56 & 5 & 0.69 \\
Lead-time & IV & 3.87 & 4 & 0.9 \\
On-time delivery & II & 4.14 & 4 & 0.91 \\
Flexibility & V & 3.22 & 3 & 1.08 \\
\hline
\end{tabular}

\#Sample size $=58$.

*Pairwise comparisons show mean of "Quality" to be statistically different from the other four variables at the $5 \%$ level.

Table 5. Descriptive statistics for likert-type scale questions (\#)

\begin{tabular}{|c|c|c|c|}
\hline \multicolumn{4}{|c|}{ Goodness-of-fit statistics: } \\
\hline $\begin{array}{l}\operatorname{LL}(0) \\
\operatorname{LL}(\beta) \\
\text { Log-likelihood ratio } \\
\text { Akaike information index (AIC) } \\
\text { Consistent akaike information index (CAIC) } \\
\text { McFadden's } \rho^{2} \\
\text { McFadden's } \rho^{2} \text { (Adj.) }\end{array}$ & $\begin{array}{r}-1022.81 \\
-248.64 \\
1548.34^{*} \\
509.28 \\
558.01 \\
0.7569 \\
0.7510\end{array}$ & & \\
\hline \multicolumn{4}{|c|}{ Parameter estimates: } \\
\hline Variable & $\beta$ & Std. error & $p$-value \\
\hline $\begin{array}{l}\text { Intercept } \\
\text { Cost } \\
\text { Quality } \\
\text { Lead-time } \\
\text { On-time delivery } \\
\text { Flexibility }\end{array}$ & $\begin{array}{r}1.0895 \\
-0.5771 \\
0.3838 \\
-0.2871 \\
0.4157 \\
0.0445\end{array}$ & $\begin{array}{l}0.1185 \\
0.1249 \\
0.1173 \\
0.1157 \\
0.1184 \\
0.1136\end{array}$ & $\begin{array}{l}0.0000 \\
0.0000 \\
0.0011 \\
0.0131 \\
0.0005 \\
0.6954\end{array}$ \\
\hline
\end{tabular}

\#The model is based on 928 responses because 58 managers responded to 16 discrete choice sets, each. $* \chi^{2}$ distributed with 6 degrees of freedom.

Table 6. Multinomial logit main effects model (\#)

analysis. McFadden's $\rho^{2}$ and adjusted McFadden's $\rho^{2}$ measures (similar to $R^{2}$ and adjusted $R^{2}$ in Ordinary Least Square regression) were found to be 0.7569 and 0.7510 , respectively. It means approximately $75 \%$ of the variation in the dependent variable (choice or tradeoff pattern) is explained by the estimated MNL regression model. Therefore it can be concluded that the empirical data fit the MNL model extremely well. The log likelihood ratio was 
estimated to be 1548.34 (w2 with 6 degrees of freedom; $p$-value < 0.05) which is statistically signi ${ }^{\circledR}$ cant at the $5 \%$ level. The other two goodness-of-fit indices AIC and CAIC were also >0, implying that the empirical data fits the estimated MNL model well. Please refer to the Appendix for information related to the goodness-of-fit statistics described above.

Table 6 also indicates that the part-worth utilities (weights or parameter estimates) for Cost, Quality, Lead-Time and On-Time Delivery are statistically significant at $a=0.05$ (the statistical significance of the $b$ parameters were estimated by NTELOGIT using an asymptotic $t$ statistic). Since the design codes for the five supplier attributes were standardized $(-1$ and +1$)$, the absolute magnitude of the $\beta$ parameters represents the relative weight of the attribute in the supplier selection process. Cost has the highest absolute value, followed by On-Time Delivery and Quality. A negative sign of parameter (for example -0.5771 for Cost) indicates that a supplier's utility (Equation (2)) will decrease if the attribute's value increases. For example, if a supplier has prices higher than its competitors (all other variables being equal), then that supplier's overall utility will be relatively lower. Similarly a positive sign of parameter implies that the overall utility will increase if the variable value is increased. For example, Table 6 shows that managers assign more weight to Cost followed by On-Time Delivery and Quality when actually choosing a supplier. Flexibility is not found to be a statistically significant attribute.

The fractional factorial design used to generate discrete choice profiles was orthogonal in nature and therefore it was possible to estimate two-way interactions among the attributes. The interaction coeffcients document the non-linear effects of the attributes on the choice process.

Since the Cost, Quality, Lead-Time and On-Time Delivery attributes were found to be statistically significant, another MNL logit model was developed which included the interaction among these four attributes, in addition to their main effects on the supplier selection process. Table 7 presents the MNL "Main Effects + Two-way Interactions" model. The log likelihood ratio (1551.88; $\chi^{2}$ with 12 degrees of freedom' $p$-value $\left.<0.05\right)$, AIC and CAIC show that the overall model fits the data well. However, the $\rho^{2}$ for this model was 0.7586 which is only slightly higher than the "Main Effects Only" model (Table 6). None of the two-way interactions was found to be statistically significant as shown in Table 7 where the non-linear effects of the attributes are negligible compared to the main effects.

\section{Discussion}

The results of the Likert-Type scale questions (Table 5) show that the managers perceive quality to be the most important attribute when selecting a supplier. This result is consistent with the past research on the topic. The standard deviations for all the variables are relatively large, therefore except quality, statistically there are no significant differences among the mean scores for the other four variables. On the other hand, the estimated logit model developed from the DCA data provides useful information for many types of strategic decisions. First of all, it shows that four independent variables are statistically significant in predicting tradeoffs in 


\begin{tabular}{|c|c|c|c|}
\hline \multicolumn{4}{|c|}{ Goodness-of-fit statistics: } \\
\hline $\begin{array}{l}\operatorname{LL}(0) \\
\operatorname{LL}(\beta) \\
\text { Log-likelihood ratio } \\
\text { Akaike information index (AIC) } \\
\text { Consistent akaike information index (CAIC) } \\
\text { McFadden's } \rho^{2} \\
\text { McFadden's } \rho^{2} \text { (Adj.) }\end{array}$ & $\begin{array}{r}-1022.81 \\
-246.87 \\
1551.88^{*} \\
517.74 \\
615.19 \\
0.7586 \\
0.7469\end{array}$ & & \\
\hline \multicolumn{4}{|c|}{ Parameter estimates: } \\
\hline Variable & $\beta$ & Std. error & $p$-value \\
\hline Intercept & 1.0997 & 0.1429 & 0.0000 \\
\hline Cost & -0.5776 & 0.1354 & 0.0000 \\
\hline Quality & 0.3745 & 0.1274 & 0.0033 \\
\hline Lead-time & -0.2980 & 0.1254 & 0.0174 \\
\hline On-time delivery & 0.4177 & 0.1293 & 0.0012 \\
\hline Flexibility & 0.0407 & 0.1258 & 0.7461 \\
\hline Cost $\times$ quality & 0.0391 & 0.1356 & 0.7731 \\
\hline Cost $\times$ lead-time & 0.0362 & 0.1356 & 0.7694 \\
\hline Cost $\times$ on-time delivery & 0.0727 & 0.1376 & 0.9578 \\
\hline Quality $\times$ lead-time & 0.0170 & 0.1285 & 0.8978 \\
\hline Quality $\times$ on-time delivery & 0.1237 & 0.1295 & 0.3394 \\
\hline Lead Time $\times$ on-time delivery & 0.1351 & 0.1292 & 0.2957 \\
\hline
\end{tabular}

\#Model based on 928 responses.

$* \chi^{2}$ distributed with 6 degrees of freedom.

Table 7. Multinomial logit main effects + selected interactions model (\#)

supplier selection process. Additionally a high McFadden $\rho^{2}$ suggests that the estimated MNL model fits the empirical data (supplier choice process) very well.

The MNL regression model shows that the managers assign more weight to cost and on time delivery compared to quality. This result is perhaps the most important finding of the study. It suggests that even though managers understand and perceive quality to be more important than cost, in practice they do not choose supplier based on quality. We believe that this result has important implications for practice and future research on supply chain management.

The estimated MNL model can be used to compare the likelihood of choosing a supplier from a group of alternatives. A simple example can illustrate the point. Assume that there are only two suppliers with the attribute levels shown in Table 8. Supplier 1 has lower costs but relatively lower quality and unreliable delivery performance while Supplier 2 has higher cost, quality and reliable delivery performance. Given the MNL parameter estimates, Table 8 shows that probability of selecting Supplier 1 is 0.3906 while probability of selecting Supplier 2 is 0.6094. The impact of change in strategies can be easily calculated from the MNL Model. For example, assume Supplier 1 increases its quality level from "minimum required" to "far exceeding minimum requirement" and Supplier 2 retains its current strategy. Then the probability of selection of Supplier 1 and Supplier 2 shift to $58 \%$ and $42 \%$, respectively. 


\begin{tabular}{lcc}
\hline Attributes & Supplier \#1 (design code) & Supplier \#2 (design code) \\
\hline Cost & lower than competitors $(-1)$ & higher than competitors $(+1)$ \\
Quality & meets minimum quality standards $(-1)$ & far exceeds minimum quality standards $(+1)$ \\
$\begin{array}{l}\text { Delivery lead-time } \\
\text { On-time delivery }\end{array}$ & longer than competitors $(+1)$ & longer than competitors $(+1)$ \\
Flexibility & sometimes late $(-1)$ & always on time $(+1)$ \\
\hline
\end{tabular}

Utility of Supplier \#1:

$V 1=1.0895+(-1) *(-0.5771)+(-1) *(+0.3838)+(+1) *(-0.2871)+(-1) *(+0.4157)+(-1) *(+0.0445)=0.5355$.

Utility of Supplier \#2:

$V 2=1.0895+(+1) *(-0.5771)+(+1) *(+0.3838)+(+1) *(-0.2871)+(+1) *(+0.4157)+(-1) *(+0.0445)=0.9803$.

Probability of choosing Supplier \#1:

$$
P_{\mathrm{c}}(1)=\frac{e^{0.5355}}{e^{0.5355}+e^{0.9803}}=0.3906
$$

Probability of choosing Supplier \#2:

$$
P_{\mathrm{c}}(2)=\frac{e^{0.9803}}{e^{0.5355}+e^{0.9803}}=0.6094 \text {. }
$$

Table 8. Using multinomial logit models: an example

\section{Conclusions and Directions for Future Research}

Leading publications in business management emphasize the need for understanding manufacturing decisions and practices for improving the competitive position of a firm. Various publications argue that it is necessary for the manufacturing decisions and choices to be consistent with the corporate strategy for effective operations management. The objective of this research was to understand one strategic operating decision area: the supplier selection process. As more manufacturing organizations adopt TQM and JIT concepts, the role of supplier and supply chain management becomes even more important.

This study was designed primarily to study how managers tradeoff among quality, cost, delivery and flexibility attributes when choosing a supplier for major components and/or raw materials. In order to compare the choice results with previous empirical studies relating to supplier selection, managers were also asked to rate the supplier attributes on a Likert-type scale. The results presented in this article show that managers perceive Quality as the most important supplier attribute. However the same sample of managers assign more weight to Cost and On Time Delivery attributes than Quality when actually choosing a supplier.

The results presented in this paper have important implications for the operations strategy and supply chain management research. It is clear that for the sample of firms studied, there is a gap between the perception and actual practice. A possible explanation for these results might be that the operating practices in the sample of firms studied are not completely consistent with their strategic priorities. It is also possible that the performance evaluation for the managers responsible for selecting suppliers are more weighted towards the cost and 
delivery performance measures and therefore even though they perceive quality to be more important, it is not the most important criterion when actual choice is made.

Anderson et al. [1] define operations strategy as a long-range vision for the operations function. The plan must be integrated with business strategy and implemented throughout the operating decision areas. They suggest that the resulting strategy based on a firm's mission, objectives, policies and distinctive competence should guide tactical operating decisions. The results presented in this article show that it is possible that the choice or actual implementation decisions might not be consistent with the stated management's vision. These results raise several interesting questions for operations strategy researchers: When can we expect a gap between the stated operations strategy and actual implementation? If such gaps do exist, how can they be reduced? How do such strategy gaps affect firm performance? Are the results presented in this paper generalizable to other industries/samples/operating functions?

The objective of this article was to investigate actual practice and choice in an important POM decision area. We have shown that studying operating choices can be a worth-while exercise for understanding operations strategy processes. Similar studies should be undertaken to further the knowledge of operations strategy process. Further studies are also required to validate the results presented in this study and obtain more generalizable results. For example, our analysis was based on a relatively small sample size, both in terms of the number of respondents and in terms of the industries studied. It is possible that the supplier selection process varies from industry to industry and/or within different geographical regions around the globe.

Since this paper was the first attempt to model actual supplier selection process using discrete choice analysis and multinomial logit model, we used two levels and only five attributes to describe the alternatives (suppliers) to the decision makers (managers). Even though the MNL models with two levels generally explain close to $75 \%$ of variation in the choice processes, they can only be used for "exploratory" type analyses. Supplier selection is a highly complex process involving influences from two or more organizations, several individuals/departments, and other operating policies. For example, the two levels of quality used in this study, "meets minimum quality level" and "far exceeds minimum quality levels", might provide an alternative explanation for Quality's lower utility (b) compared to Cost. It can be argued that once the components/raw materials reach the minimum acceptable quality level, management's focus often shifts to Cost reduction. Similarly, adding more attributes in the experimental design (for example, multidimensional quality attributes \pm features, reliability, durability, ... of components) might provide additional insights to the complex process of supplier selection.

\section{Appendix}

\section{Goodness-of-Fit Statistics}

An asymptotic t-statistic (similar to a t-test in the OLS regression) can be calculated for 
estimated $\beta$ parameters in MNL model. Several likelihood ratio tests (similar to an F-test in OLS regression) can be used to test the overall MNL model. A log-likelihood ratio test is based on the differences between the natural logarithm of the likelihood function (Equation (3)) under two conditions. First the likelihood ratio is calculated assuming equal probability of choosing all the alternatives in a choice set or by assuming all $b$ parameters to be zero. This natural logarithm of the likelihood (log-likelihood) value is represented as LL(0). Next, the likelihood ratio is calculated again, assuming the estimated $\beta$ parameters. This log-likelihood value is called $\operatorname{LL}(\beta)$. Then, the log-likelihood ratio test is defined as

$$
-2[L L(0)-L L(\beta)]
$$

and is $\chi^{2}$ distributed with the degrees of freedom equal to the number of $\beta$ parameters. Other goodness-of-fit measures called Akaike Information Criteria (AIC) and Consistent Akiake Information Criteria (CAIC) are defined in the following manner:

$$
\begin{gathered}
A I C=-2[L L(\beta)-\text { number of } \beta \text { parameters }] \\
C A I C=-2[L L(\beta)-\text { number of } \beta \text { parameters }(1+\ln M)]
\end{gathered}
$$

For a "good" model both AIC and CAIC should be positive [5]. McFadden's $\rho^{2}$ and adjusted McFadden's $\rho^{2}$ measures (similar to $R^{2}$ and adjusted $R^{2}$ in OLS regression) are defined in the following manner:

$$
\begin{gathered}
\rho^{2}=1-\left[\frac{L L(\beta)}{L L(0)}\right] \text { and } 0 \leq \rho^{2} \leq 1 \\
\text { Adj. } \rho^{2}=1-\left[\frac{L L(\beta)-\text { number of } \beta \text { parameters }}{L L(0)}\right] \text { and } 0 \leq \text { Adj. } \rho^{2} \leq 1
\end{gathered}
$$

For additional information on discrete choice analysis and MNL models please refer to the text by Ben-Akiva and Lerman [5].

\section{References}

1. Anderson, J. C., Cleveland, G. and Schroeder, R. G., Operations strategy: A literature review. J. Ops. Mgmt, 1989, 8, 133 \pm 158 .

2. Ansari, A. and Modarress, B., JIT purchasing as a quality and productivity center. Int. J. Prod. Res., 1980, 26, 19 \pm 26 .

3. Ansari, A. and Modarress, B., Just-in-time purchasing: Problems and solutions. J. Purch. Mater. Mgmt, 1986, 22, 11 \pm 15 .

4. Banker, R. D. and Khosla, I. S., Economics of operations management: A research perspective. J. Ops. Mgmt, 1995, 12, 423 \pm 425 .

5. Ben-Akiva, M. and Lerman, S. R. (1991) Discrete Choice Analysis. MIT Press, Cambridge, MA. 
6. Benton, W. C. and Krajeski, L., Vendor performance and alternative manufacturing environments. Decis. Sci., 1990, 21, 403 \pm 415 .

7. Bernard, P., Managing vendor performance. Prod. Invent. Mgmt J., 1989, 30, $1 \pm 7$.

8. Bishop, Y. M., Fienberg, S. E. and Holland, P. W. (1975) Discrete multivariate analysis: Theory and practice. MIT Press, Cambridge, MA.

9. Browning, J. M., Zabriskie, N. B. and Huellmantel, A. B., Strategic purchasing planning. J. Purch. Mater. Mgmt, 1983, 19, $19 \pm 24$.

10. Burton, T. T., JIT/Repetitive sourcing strategies: "Tying the knot" with your suppliers. Prod. Invent. Mgmt J., 1988, 29, 38 \pm 41 .

11. Cardozo, R. N. and Cagley, J. W., Experimental study of industrial buyer behavior. J. Mktg Res., $1971,8,329 \pm 334$.

12. Chapman, S. N., Just-in-time supplier inventory: An empirical implementation model. Int. J. Prod. Res., 1993, 27, 1993 \pm 2007.

13. Chapman, S. N. and Carter, P. L., Supplier/customer inventory relationships under just-intime. Decis. Sci., 1990, 21, 35 \pm 51 .

14. Dempsey, W. A., Vendor selection and the buying process. Ind. Mktg. Mgmt., 1978, 7, $257 \pm 267$.

15. Dickson, G. W., An analysis of vendor selection systems and decisions. J. Purch., 1966, 2, $5 \pm 17$.

16. Ferdows, K. and DeMayers, A., Lasting improvements in manufacturing performance: In search of a new theory. J. Ops. Mgmt., 1990, 9, 168 \pm 184 .

17. Flynn, B. B., Sakakibara, S., Schroeder, R. G., Bates, K. A. and Flynn, E. J., Empirical research methods in operations management. J. Ops. Mgmt., 1990, 9, $250 \pm 284$.

18. Flynn, B. B., Schroeder, R. G. and Sakakibara, S., A framework for quality management research and an associated measurement instrument. J. Ops. Mgmt., 1994, 11, 339 3666 .

19. Gensch, D. H. and Recker, W. W., The multinomial, multiattribute logit choice model. J.

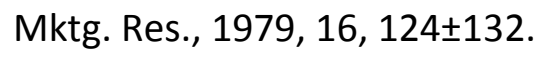

20. Green, P. and Srinivasan, V., Conjoint analysis in consumer research: Issues and outlook. J. Consum. Res., 1978, 5, 103 \pm 123 .

21. Green, P. E. and Tull, D. S. (1978) Research for Marketing Decisions. Prentice Hall, Englewood Cliffs, NJ.

22. Greenberg, M. G., Commentary . Mktg Sci., 1986, 5,320 321 . 
23. Hagerty, M. R., The cost of simplifying preference models. Mktg. Sci., 1986, 5, $298 \pm 319$.

24. Hahn, C. K., Pinto, P. A. and Bragg, D. J., Just-in-time production and purchasing. J. Purch. Mater. Mgmt., 1983, 19, 2ะ10.

25. Hahn, G. J. and Shapiro, S. S. (1966) A catalog and computer program for the design and analysis of orthogonal symmetric and asymmmetric fractional factorial experiments, Technical Report Number 66-C

165. General Electric Research and Development Center.

26. Hakansson, H. and Wootz, B., Supplier selection in an international environment: An

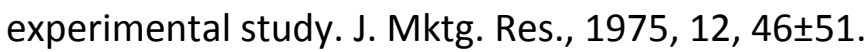

27. Hayes, R. H. and Wheelwright, S. C. (1984) Restoring our competitive edge: Competing through manufacturing. John Wiley \& Sons, New York, NY.

28. Jackson, G. C., Just-in-time production: Implications for logistics managers. J. Bus. Logist., $1983,4,1 \pm 19$.

29. Karmarker, U. S., Integrative research in marketing and operations management. J. Mktg. Res., 1996, 33, 125 \pm 133 .

30. Kraljic, P., Purchasing must become supply management. Harv. Bus. Rev., 1983, 61, $109 \pm 117$.

31. Louviere, J. J., Using discrete choice experiments and multinomial logit choice models to forecast trial in a competitive retail environment: A fast food restaurant illustration. J.

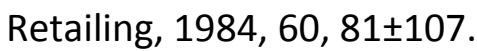

32. Louviere, J. J. (1988) Analyzing Decision Making: Metric Conjoint Analysis. SAGE Publications, Newbury Park, CA.

33. McFadden, D., The choice theory approach to market research. Mktg Sci., 1986, 5, $275 \pm 297$.

34. McLean, R. and Anderson, V. (1984) Applied Factorial and Fractional Designs. Marcel Dekker, New York, NY.

35. Miller, J. G. et al., Production/operations management: Agenda for the ' 80 s. Decis. Sci., $1981,12,547 \pm 571$.

36. Monczka, R. M., Guinipero, L. C. and Reck, R. F., Perceived importance of supplier information. J. Purch. Mater. Mgmt., 1981, 17, $21 \pm 29$.

37. NTELOGIT. (Intelligent Marketing Systems, Edmonton, Canada, 1992).

38. Sheth, J. N., A model for industrial buyer behavior. J. Mktg., 1973, 37, 50 \pm 56 . 
39. Treleven, M., Single sourcing: A management tool for the quality supplier. J. Purch. Mater. Mgmt, 1987, 23, 19 \pm 24 .

40. Verma, R. and Thompson, G. M., Basing service management on customer determinants: The importance of hot pizza. Cornell Hotel Rest. Adm. Q., 1996, 37, $18 \pm 23$.

41. Wagner, J., Ettenson, R. and Parrish, J., Vendor selection among retail buyers: An analysis by merchandise division. J. Retailing, 1989, 65, 58 \pm 77 .

42. Weber, C. A. and Current, J. R., A multiobjective approach to vendor selection. Eur. J. Oper. Res., 1993, 68, 173 \pm 184 .

43. Weber, C. A., Current, J. R. and Benton, W. C., Vendor selection criteria and methods. Eur. J. Oper. Res., 1991, 50, 2ะ18. 